Prepared for the U.S. Department of Energy under Contract DE-AC05-76RL01830

US National Climate Assessment (NCA) Scenarios for Assessing Our Climate Future: Issues and Methodological Perspectives Background Whitepaper for Participants

$\begin{array}{ll}\text { RH Moss } & \text { S O’Brien } \\ \text { NL Engle } & \text { C Rozenzweig } \\ \text { J Hall } & \text { A Ruane } \\ \text { K Jacobs } & \text { S Sheppard } \\ \text { R Lempert } & \text { RW Vallario } \\ \text { LO Mearns } & \text { A Wiek } \\ \text { J Melillo } & \text { T Wilbanks } \\ \text { P Mote } & \end{array}$

\title{
October 2011
}

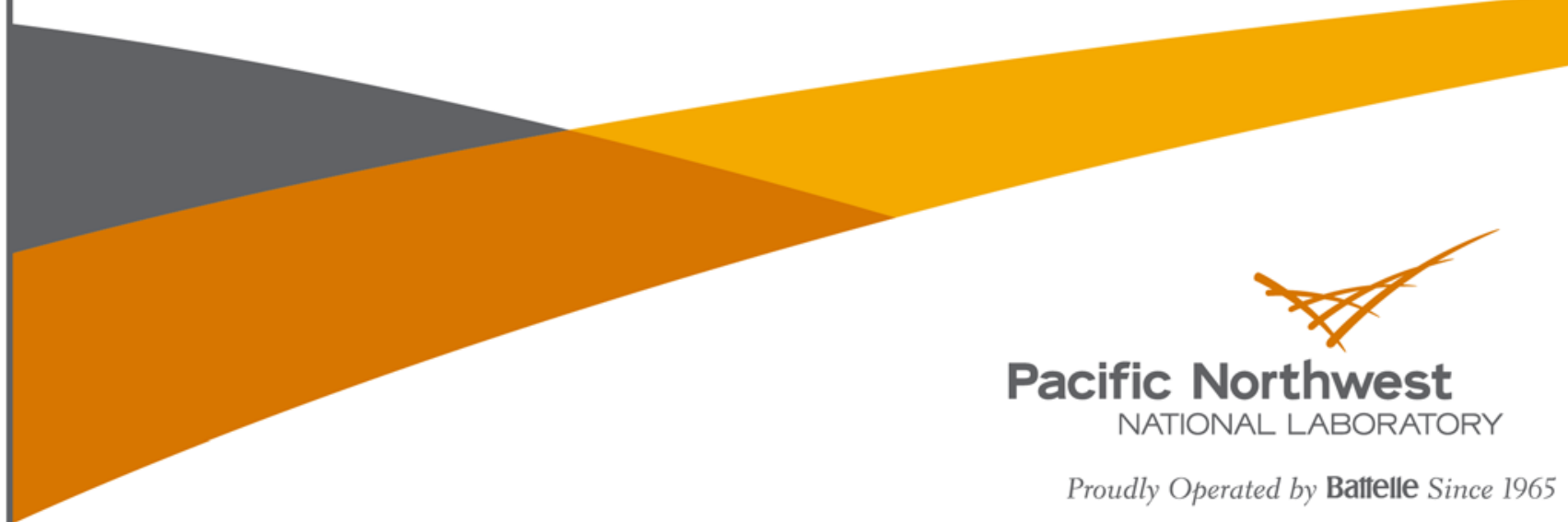





\section{DISCLAIMER}

This report was prepared as an account of work sponsored by an agency of the United States Government. Neither the United States Government nor any agency thereof, nor Battelle Memorial Institute, nor any of their employees, makes any warranty, express or implied, or assumes any legal liability or responsibility for the accuracy, completeness, or usefulness of any information, apparatus, product, or process disclosed, or represents that its use would not infringe privately owned rights. Reference herein to any specific commercial product, process, or service by trade name, trademark, manufacturer, or otherwise does not necessarily constitute or imply its endorsement, recommendation, or favoring by the United States Government or any agency thereof, or Battelle Memorial Institute. The views and opinions of authors expressed herein do not necessarily state or reflect those of the United States Government or any agency thereof.

\section{PACIFIC NORTHWEST NATIONAL LABORATORY}

$$
\begin{aligned}
& \text { operated by } \\
& \text { BATTELLE } \\
& \text { for the }
\end{aligned}
$$

\section{UNITED STATES DEPARTMENT OF ENERGY} under Contract DE-AC05-76RL01830

Printed in the United States of America Available to DOE and DOE contractors from the Office of Scientific and Technical Information, P.O. Box 62, Oak Ridge, TN 37831-0062; ph: (865) 576-8401 fax: (865) 576-5728 email: reports@adonis.osti.gov

Available to the public from the National Technical Information Service, U.S. Department of Commerce, 5285 Port Royal Rd., Springfield, VA 22161 ph: (800) 553-6847 fax: (703) 605-6900

email: orders@ntis.fedworld.gov online ordering: http://www.ntis.gov/ordering.htm This document was printed on recycled paper. 



\section{US National Climate Assessment (NCA) Scenarios for Assessing Our Climate Future: Issues and Methodological Perspectives Background Whitepaper for Participants ${ }^{1}$ PNNL-SA20040}

Richard Moss, Nathan Engle, John Hall, Kathy Jacobs, Robert Lempert, Linda Mearns, Jerry Melillo, Phil Mote, Sheila O’Brien, Cynthia Rosenzweig, Alex Ruane, Stephen Sheppard, Bob Vallario, Arnim Wiek, and Tom Wilbanks.

\section{Introduction}

This whitepaper was originally drafted as background for a workshop for the National Climate Assessment (NCA) that focused on the use and development of scenarios. The paper is being published as a chapter in the report of the workshop because the authors and members of the organizing committee believe it conveys information of use to participants in the assessment process, and the broader research and user communities that work with scenarios in climate science. The paper briefly defines key terms and establishes a conceptual framework for developing consistent scenarios across different end uses and spatial scales. It reviews uses of scenarios in past U.S. national assessments and identifies potential users of and needs for scenarios for both the report scheduled for release in June 2013 and to support an ongoing distributed assessment process in sectors and regions around the country. Because scenarios prepared for the NCA will need to leverage existing research, the paper takes account of recent scientific advances and activities that could provide needed inputs. Finally, it considers potential approaches for providing methods, data, and other tools for assessment participants.

\footnotetext{
${ }^{1}$ This document was prepared as a background whitepaper for participants at a workshop held in December 2010 in Arlington, VA to explore needs, options, and research for the development of scenarios to support science and assessment of climate and global change over the coming decades. The overall effort was lead by the science community, and coordinated through a research community steering group. Responding to the interagency U.S. Global Change Research Program (USGCRP), the workshop was sponsored by the U.S. Department of Energy's Office of Biological and Environmental Research. The purpose, scope, and objectives of the effort were informed by inputs from a federal coordinating committee comprised of representatives of participating USGCRP agencies. The workshop brought together leading researchers, scenario developers, stakeholders, and federal officials to examine the potential uses of scenarios in research on and assessments of climate change and response options. The results also have significant implications for climate research beyond assessments, improving understanding of the current scientific basis for scenario development and identifying methods for improving consistency in their use and interpretation. The workshop included plenary session presentations and panels as well as breakout group discussion. This version is revised from the first draft discussed at the workshop. The authors thank the workshop participants for their comments, which have improved the draft. A final report of the workshop which includes a letter report from the steering committee as well as a summary of workshop discussion in plenary sessions and breakout groups is available from the USGCRP website: http://www.globalchange.gov/ .
} 
We note that the term "scenarios" has many meanings. An important goal of the whitepaper (and portions of the workshop agenda) is pedagogical (i.e., to compare different meanings and uses of the term and make assessment participants aware of the need to be explicit about types and uses of scenarios).

In climate change research, scenarios have been used to establish bounds for future climate conditions and resulting effects on human and natural systems, given a defined level of greenhouse gas emissions. This quasi-predictive use contrasts with the way decision analysts typically use scenarios (i.e., to consider how robust alternative decisions or strategies may be to variation in key aspects of the future that are uncertain).

As will be discussed more fully below, in climate change research and assessment, scenarios describe a range of aspects of the future, including major driving forces (both human activities and natural processes), changes in climate and related environmental conditions (e.g., sea level), and evolution of societal capability to respond to climate change. This wide range of scenarios is needed because the implications of climate change for the environment and society depend not only on changes in climate themselves, but also on human responses. This degree of breadth introduces and number of challenges for communication and research.

\section{I.1 Definitions and types of scenarios}

In this whitepaper, the term "scenarios" will be used to describe qualitative and quantitative information about different aspects of the future developed to investigate the potential consequences of climate change. There are a number of excellent general references on the use of scenarios in climate change research. This paper draws heavily on Parson et al., 2007, a review of scenarios prepared as one of the U.S. Climate Change Science Program (CCSP) Synthesis and Assessment Products. Drawing on this review and other references, this whitepaper classifies scenarios according to their content and the types of models or methods used to produce them. According to this typology, the major types of scenarios relevant to the NCA include:

Emissions scenarios are descriptions of potential future emissions to the atmosphere of greenhouse gases and other radiatively important gases and particles that are used to explore the implications of alternative energy and technology futures and provide inputs to climate models. Emissions scenarios are not forecasts or predictions. They focus on longterm (e.g., decades to centuries) trends in energy and land-use patterns, not short-term fluctuations. They are developed using integrated assessment models and are based on research into socioeconomic, environmental, and technological trends. Uncertainty in emissions scenarios results from the inherent uncertainty of future socioeconomic and technology conditions and differences in representations of processes and relationships across models, among other factors. For a recent evaluation of the emissions scenario literature, see Fisher et al., 2007. For an overview of integrated assessment modeling approaches, see Weyant et al., 1996. 
Climate scenarios are plausible representations of future climate conditions (temperature, precipitation, and other factors) produced using a variety of techniques including scaling of observed climate, spatial and temporal analogues in which climates from other locations or periods are used as example future conditions, extrapolation and expert judgment, and mathematical climate and Earth system models. All of these techniques continue to play a useful role in development of scenarios, with the appropriate choice of method depending on the intended use of the scenario. Regional-scale climate scenarios and projection methods for impact and adaptation assessment are highly relevant for the NCA. See Mearns et al, 2001.

Environmental scenarios focus on changes in environmental conditions such as water availability and quality, sea level rise (incorporating geological and climate drivers), land cover and use, and air quality. Climate change can drive changes in these factors, or scenarios can represent independently caused variations. The potential impact of climate change and the effectiveness of adaptation options cannot be understood without examining interactions of changes in climate, environmental conditions, and human responses. See Carter et al., 2001.

Socio-economic scenarios for assessment of impacts, adaptation, and vulnerability project future demographic, economic, institutional, and other characteristics that are needed for different types of impact modeling and research. This information is crucial for evaluating the potential to be affected by changes in climate as well for examining how different types of economic growth and social change affect the capacity to adapt to potential impacts. Many of the same socioeconomic factors that affect emissions also affect vulnerability and adaptive capacity and thus the underlying socioeconomic modeling must be coordinated. For an overview of socioeconomic driving forces, see Nakicenovic et al., 2000. For a recent description of needs for socioeconomic scenarios and narratives, see NRC, 2010.

Narratives describe in qualitative form political, institutional, and other factors that influence future forcing, vulnerability, and responses. Narratives are useful because while some socioeconomic factors affecting emissions and vulnerability are modeled quantitatively, others are not effectively quantified. Narratives can be used as the basis for quantitative scenarios, as in the IPCC SRES (Nakicenovic et al., 2000). They can also facilitate coordination across spatial scales and substantive domains (see Zurek and Hendrichs, 2007, and NRC, 2010). More broadly, narratives are "stories" about the future that are strategically-developed to lead decisionmakers ("end-users") to consider futures and potential responses that they might have otherwise neglected but that are nonetheless important. The use of scenarios as explicit decision support tools contrasts with the ways in which narratives can be employed by researchers to coordinate studies across scales or sectors.

Other typologies of scenarios are also available and focus on audience, use, and other characteristics. Bradfield et al., 2006 have categorized scenarios into three schools: intuitive logics (exemplified by the work of Rand, the Global Business Network, and Shell), in which a small number of diverse scenarios are crafted that help decisionmakers 
understand the most important drivers of their future and how best to respond); "La Prospective" or other backcasting methods (e.g., Godet, Berger) in which desirable futures are defined and the scenarios specify how these visions might be attained; and Probabilistic Modified Trends (e.g., Gordon, Helmer), which aim to add surprise to traditional forecasting methods. Another typology, proposed by van Notten et al., 2003, differentiates scenarios according to their goal (raising awareness or decision support); the process used to create them (interactive group sessions or a formal process employing quantified knowledge); and the scenario content (complex or simple).

\section{I.2 Users}

Two broad categories of users of scenarios are often distinguished: intermediate users (modelers and other members of the research community) and end-users (decisionmakers, stakeholders, and others). This distinction is established here, briefly described, and further developed in subsequent sections of the whitepaper, especially section IV, which focuses on potential scenario products for different sets of intermediate and end users.

Intermediate users: In previous assessments (NCA 2000 and NCA 2009), scenarios were developed primarily for intermediate scientific users to provide information from one area of research to another (e.g., from research on energy systems and greenhouse gas emissions to climate modeling-see Figure 1). This effort was essential for researching and writing the assessment reports themselves and is described in more detail in section III below). The need to coordinate and integrate different types of analysis with scenarios will be important for preparing the NCA 2013 report.

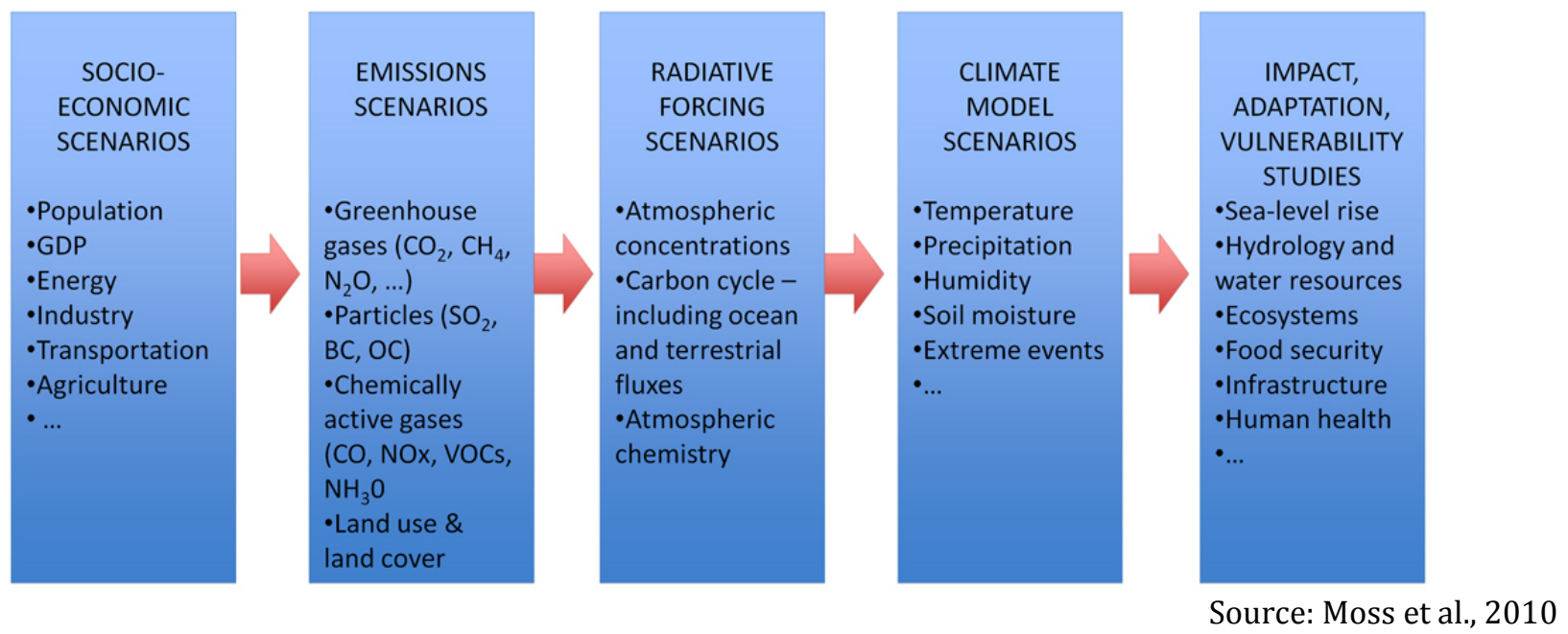

Figure 1: Typical sequential hand off of information across scientific disciplines using a range of scenario types

End users: this category of users is very diverse and includes elected officials, resource managers, land-use or urban planners, entrepreneurs, analysts and executives in the private sector, non-governmental organizations, citizens, and many others who are the 
ultimate audience of assessments and/or who wish to assess the need to take account of climate change in their future activities and plans. By design, the scenarios workshop did not involve end users but instead relied on inputs from other workshops supporting the NCA that did include them (e.g., see section IV.2 below for a summary of needs identified at an NCA workshop on sectors and regions). The workshop did include individuals who work in "boundary" or "bridging" organizations that interact with a variety of end users by interpreting and assisting with application of scenarios and other research-based methods of decision-support.

In the long-term NCA process, greater emphasis will be given to providing tools and building capacity to support assessment and deliberation at local, state, and regional levels. To facilitate these distributed activities and future NCA reports, it will be necessary to develop methodologies that can be adapted and applied across a range of regions and sectors of the U.S. For these uses, greater attention will be paid to developing participatory scenario processes that enable end users and local analysts to consider context-specific decisions throughout a range of climate, socioeconomic, and environmental scenarios. The primary audience for these scenarios and scenario products will be those regional and local decisionmakers who are developing climate action plans or simply want to reflect upon ways in which climate change may affect their interests. The purpose of scenarios for these individuals is to improve decisionmaking by helping practitioners consider alternative climate futures and impacts, identify key vulnerabilities, and gauge adaptive and mitigative capacity, among others. For example, managers might use the NCA environmental and socioeconomic scenarios to help draft a forest management plan for a given region, or use narratives to perform long-term visioning and planning for their community.

An underlying issue related to the use of scenarios in decisionmaking is whether probabilities can be usefully associated with scenarios (e.g., Schneider, 2001; Grubler and Nakicenovic, 2001; Pittock et al., 2001; Katz, 2002; Desai and Hulme, 2004; Knutti et al., 2005; Hall, 2007.) The motivation for providing probabilistic representations of scenarios is that without quantification of relative likelihoods, decisionmakers will have insufficient information upon which to base decisions or will develop their own assessments of relative likelihood that depart from the best judgment of experts. A number of concerns have been raised, however, including that the resulting estimates may overstate existing knowledge of probabilities of different potential futures, under-represent uncertainty, or that even attempting to attach probabilities to scenarios conflicts with their proper use in decisionmaking contexts. Another concern regarding use of scenarios is that users can develop overconfidence in them. Any scenario or set of scenarios will represent only a small fraction of possible futures, yet when people may interpret them, they can believe that they represent all or the most important or likely possibilities. Overconfidence is particularly likely without the explicit assignment of probabilities to specific scenarios. However, as discussed above, the assignment of probabilities is controversial. It is thus essential that scenarios prepared for use in the NCA be accompanied by clear guidance on their interpretation, uses, and limits. 


\section{Overview of Strategy for NCA 2013 and Ongoing Distributed Climate Assessments}

\section{II.1 Vision and goals}

Scientific assessments serve as progress reports by identifying advances in the underlying science, providing critical analysis of issues, highlighting important findings and key unknowns that can improve policy choices, and guiding decisionmaking related to climate change. The approach that is envisioned for the NCA 2013 is a comprehensive assessment of climate change, impacts, vulnerabilities and adaptations, within a context of how communities and the nation as a whole work to create sustainable and environmentally sound development paths.

The vision for the NCA 2013 is to establish a continuing, inclusive national process that:

- synthesizes relevant science and information;

- increases understanding of what is known and not known;

- $\quad$ identifies needs for information related to preparing for climate variability and change and reducing climate impacts and vulnerability;

- evaluates progress of adaptation and mitigation activities;

- informs science priorities;

- builds assessment capacity in regions and sectors; and

- builds societal understanding and skilled use of Assessment findings.

\section{II.2 Mandate and focus}

The mandate for the assessment is contained in the Global Change Research Act (GCRA) of 1990 (see, http://www.gcrio.org/gcact1990.html). Section 106 specifies that a "Scientific Assessment" must be prepared not less frequently than every four years and delivered to the President and Congress. This assessment must:

- integrate, evaluate, and interpret the findings of the Global Change Research Program, and discuss the scientific uncertainties associated with such findings;

- analyze the effects of global change on the natural environment, agriculture, energy production and use, land and water resources, transportation, human health and welfare, human social systems, and biological diversity; and

- analyze current trends in global change, both human- induced and natural, and project major trends for the subsequent 25 to 100 years.

This last requirement to analyze trends into the future requires the use of physical models at various scales, but also the ability to build scenarios that help describe and analyze future conditions where changes in climate are only one of a myriad of changing variables.

Although the definition of regions to be used in NCA 2013 is still very much in flux, it has been noted that the ability to deploy information on the web would significantly relieve the pressure on how to define the boundaries. If the Assessment can "nest" information within 
a number of national, regional and local scales the exact boundaries of the regions become much less important. That said, at the recent regional and sectoral workshop many participants felt that regions roughly analogous to those used in the 2009 report would be desirable, with adjustments to use state boundaries wherever possible. There is a strong desire for both understanding regional climatology and having the capacity to project conditions at the regional level, and at multiple time scales, including seasonal to interannual, decadal, and 50-100 years. The need to understand change in both a transient and end-point framework was also noted. Finally, the significant focus on engagement and communications raises special challenges for the intermediate user groups, who may be asked to help build coherent storylines for the future at the regional scale.

In addition to preparing the NCA 2013, the NCA seeks to build distributed national capacity to assess the implications of climate and global change both inside and beyond the federal government. This ongoing process will draw upon the work of stakeholders and scientists across the country. Assessment activities will result in the capacity to do ongoing assessments of vulnerability to climate stressors, observe and project impacts of climate change within regions and sectors, develop consistent indicators of progress in reducing vulnerability, and allow for the production of a set of reports and web-based products that are useful for decision-making at multiple levels.

\section{II.3 Process and implications for delivery of scenarios}

Overall direction for the NCA will be provided by a National Climate Assessment Development and Advisory Committee (NCADAC) to be constituted under the Federal Advisory Committee Act (FACA) by the Department of Commerce. The NCADAC will be charged with integrating and evaluating the findings of the USGCRP and balancing scientific, engineering, educational, legal, and policy expertise. The roles of a variety of organizations in preparing, reviewing, resourcing, and providing oversight for the NCA are illustrated in Figure 2. 


\section{Suggested Assessment Structure}

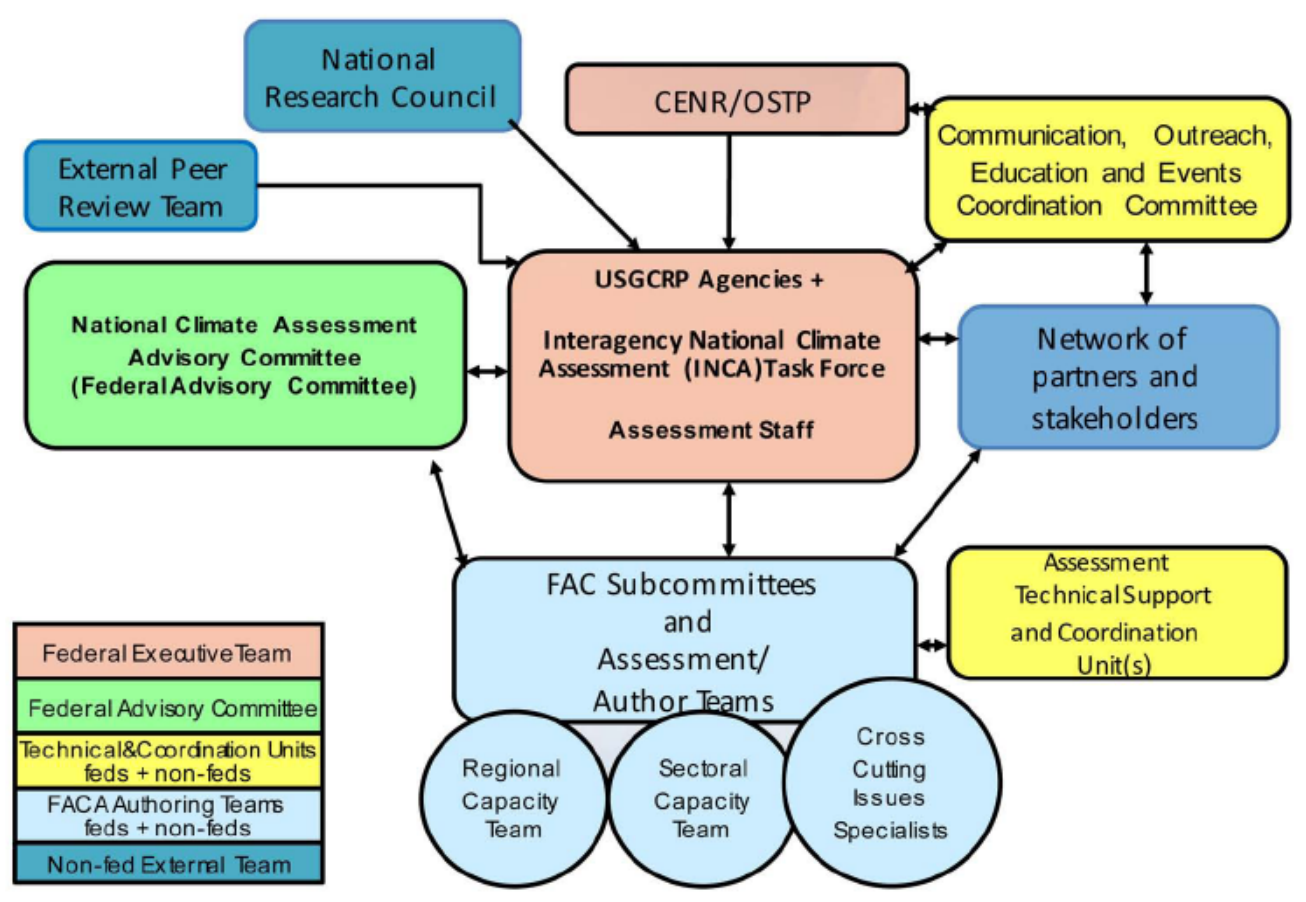

Source: K. Jacobs

Figure 2: Suggested assessment structure

Major milestones in the work plan for the assessment include: completion of a series of methodological workshops; completion of the regional and sectoral workshops; completion of a rough draft; and completion of the report to the President and Congress by June of 2013. Socioeconomic and climate data and scenarios should be provided to the regional and sectoral teams by the middle of 2011 to maximize the utility of that information to the Assessment process. An important consideration in the process is ensuring adequate opportunity for peer review and public comment on the draft assessment before its completion. See http://assessment.globalchange.gov for a more detailed timeline and updates on the assessment process.

\section{Past Uses of Scenarios in NCA 2000 and NCA 2009}

A range of scenarios were developed and provided for both the 2000 and 2009 national assessments, which were very different processes in character and extent (NAST, 2001; Karl et al., 2009). The NCA 2000 included attention to establishing an ongoing assessment process and produced a concise overview report, foundational reports for eight megaregions (and most sub-regions, including underlying technical reports), five sectors, and a report on native peoples and homelands. Unfortunately, support to maintain the ongoing assessment process was not sustained because of a change in focus in the climate research program under the George W. Bush administration de-emphasizing consequences of climate change and stressing climate forcing and processes (CCSP 2003). The NCA 2009 
report summarized information contained in 21 "Synthesis and Assessment Products" (SAPs) produced by the research program when it was known as the "Climate Change Science Program" from 2002-2009.

This section of the whitepaper summarizes the types of scenarios that were provided and developed for each report and how the scenarios were actually applied.

\section{III.1 Climate Change Impacts on the United States: The Potential Consequences of Climate Variability and Change (NCA 2000)}

Three basic categories of scenarios were developed and used for the 2000 Assessment; climate, ecosystem/vegetation, and socioeconomic (see MacCracken et al., 2001; Melillo et al., 2001; and Parson et al., 2001). The sections below provide a brief review of each of the categories, followed by preliminary lessons and questions that might inform development and use of scenarios for NCA 2013 and the ongoing assessment process.

\section{Climate Scenarios}

To ensure use of up-to-date results and to promote consistency across the broad number of research teams participating in Assessment, the National Assessment Synthesis Team (NAST) developed a set of guidelines to identify simulations to be considered for use by the regional and sector teams of the NCA 2000. For a variety of reasons discussed in MacCracken et al., 2001, two model simulations (one developed by the Canadian Centre for Climate Modelling and Analysis (CGCM1) and the other by Hadley Centre for Climate Prediction and Research of the Meteorological Office of the United Kingdom (HadCM2)) were recommended, both forced with the IPCC IS92a emissions baseline scenario. The full range of variables relevant for analysis of impacts was available through the modeling teams. The climate scenarios chapter of the assessment report provided a detailed analysis of the simulation results, focusing on a select set of variables and processes including temperature, precipitation, soil moisture, sea ice and level, extreme events, etc.

Authors used these two model simulation results, but several of the regions and sectors went beyond the two suggested GCM models and used a broader range of models and projections. The use of additional GCM models within some of the regions and sectors stemmed from a variety of factors, including the perceived lack of fit between the Hadley and Canadian models for a given region, greater capacity and financial resources that allowed more comprehensive model exploration, and a mismatch of timing between when modeling studies were commissioned within the regions and sectors and when the NAST suggested which GCMs to use. In addition, some used various data sets and downscaling techniques to interpolate data on finer spatial or temporal scales (e.g., Vegetation/Ecosystem Modeling and Analysis Project (VEMAP) for ecosystem responses, meso-scale models guided by the GCM output as boundary conditions, and statistical downscaling based on local climate data). 
Several of the major concerns and challenges with the climate scenarios identified by Morgan et al., 2005, MacCracken 2000, and in research for this Whitepaper included: perceived lack of relevance of the two models in some of the regions (i.e., the region's questions were not really answered by the model output); uncertainty caused by the wide range of model projections between the two climate scenarios; and the limited use of historical data and sensitivity analyses (the other two modeling methods suggested for projecting future climate changes).

\section{Ecosystems/Vegetation Scenarios}

VEMAP was the primary model used to generate future ecosystems scenarios for the conterminous U.S. The VEMAP outputs were based on the two Hadley and Canadian GCM model simulations, and the assessment groups used the scenarios to assist in sensitivity analyses. Outputs were based on biogeochemistry models in the near term (2025-2034) and biogeography models in the longer-term (2090-2099). Application of vegetation and ecosystem scenarios varied across regions and sectors, with some using a historical climate dataset developed for use with VEMAP to provide gridded monthly averages for key variables, and others reviewing literature and soliciting expert and stakeholder input to understand how ecosystems would respond to various climate changes.

The major concerns and challenges included: their lack of comprehensive use across all regions and relevant sectors; and an insufficient linking between the ecosystems/vegetation scenarios and socioeconomic scenarios to inform impact and adaptation analyses. These concerns and their implications for the modeling strategy in the NCA 2013 were addressed more fully in a subsequent workshop on models (December 8$10,2010)$.

\section{Socioeconomic Scenarios}

As mentioned above, the socio-economic and emissions scenarios used to force the GCM simulations used in the assessment corresponded to the IPCC IS92a scenario (a mid-range "business as usual" emissions scenario with middle of the road socioeconomic assumptions with respect to demographic, economic, and other conditions). Socioeconomic scenarios were also explicitly developed to provide context for evaluation of impacts, vulnerabilities, and adaptations. This involved both a centralized, or top-down track, and a decentralized, or bottom-up track.

The centralized track focused on providing county-level projections of a few key variables relevant to all regions and sectors to 2030, and aggregate national-scale projections to 2100. In the short-term (2030), three projections (high, middle, and low for all variables) depended upon varying assumptions of fertility, mortality, migration, labor-force participation, and productivity by age group, based on data from sources such as the Census Bureau. The projections were run using a commercial regional economic growth model, provided by NPA Data Services, which calculated annual population projections by sex and five-year age cohort for each state, county, and metropolitan area. Consistency was not established between the socioeconomic forcing scenarios (which used the IS92a 
assumptions) and these detailed 2030 projections (which were not based on IS92a assumptions). The longer-term socioeconomic projections to 2100 were only made available at the aggregate national level. These three longer-term scenarios were developed with an integrated assessment model and were intended to be consistent with three of the IPCC SRES scenarios. Evaluation of differences in the socioeconomic scenarios that resulted from the use of different assumptions and sources (IS92a, SRES, and Census Bureau) was not performed. A question to be explored in developing socioeconomic scenarios for NCA 2013 is the degree of consistency needed across scenario components.

The decentralized track provided a common method for assessment teams to use to develop their own socioeconomic projections of factors of greatest local (or sectoral) interest beyond the three variables projected in the centralized track. Also, within the decentralized track, in an exploratory approach using narratives, assessment teams were encouraged to walk through plausible socioeconomic conditions that might lead to a range of impacts, scouting for possible vulnerabilities and opportunities that might escape notice in a more conventionally structured inquiry.

Major concerns and challenges with the socioeconomic scenarios pertained mainly to their lack of use and questions about their relationship with the climate and ecosystems/vegetation scenarios. Assessment teams rarely used the centralized track, and utilized the decentralized track and exploratory approach even less. When socioeconomic scenarios were used, quantitative projections were prioritized over constructing storylines of alternative socioeconomic futures. In the few instances that a team did consider the context-specific variables, the scenarios became overly complex, making them less plausible in hindsight. When neither quantitative projections nor qualitative narratives were used, literature reviews, expert judgment, and case studies were used. As Morgan et al., 2005 point out, the majority of assessment participants surveyed after the NCA 2000 suggested that the social and economic impacts should be handled differently in future iterations of the Assessment, albeit with little agreement on how to do so.

\section{III.2. Global Change Impacts in the United States (NCA 2009)}

In NCA 2009, scenarios were primarily used to provide context and illustration, rather than to stimulate analyses and assessments at the regional or sectoral level, as was the original (and only partially realized) intent in NCA 2000. A shortened timeframe for producing this report (i.e., approximately 13 months) limited the opportunity for engagement of regional and sectoral stakeholders, as well as reliance on conclusions from the CCSP SAPs and the IPCC Fourth Assessment, were among the reasons for this approach.

For climate change information, the 2009 Assessment used 16 models simulations from the WCRP CMIP3 for the conterminous U.S. For Alaska, projections were based on 14 models that best captured the present climate of the state. Caribbean and Pacific islands analyses used 15 models simulations from the WCRP CMIP3 that were available at finer scale resolutions. The runs were forced by the SRES A2 and B1 emissions, and for some applications a high-emissions scenario (A1-"Fossil-Intensive" or A1FI) was also used. Based 
on CMIP3 runs, the 2009 NCA offered broad interpretations and maps of the potential future regional implications of climate change for the U.S. Interpreting the results of the CMIP projections created some debate within the 2009 NCA author team. For example, in producing the precipitation maps, there were some areas where most models agreed, but other aspects where interpretation of the model output was less straightforward (e.g., fixing the latitudinal gradient of changes in precipitation). Downscaling was performed for a number of regions, and the results of this exercise informed a number of analyses and products within the assessment (e.g., "migrating states" maps, heat stress and mortality projections for selected cities around the country, trends in peak streamflow timing for the West, Gulf Coast roads at risk from sea-level rise, and vegetation shifts in the Northeast, to name a few).

Unlike the NCA 2000, the NCA 2009 did not develop detailed socioeconomic scenarios for use in impacts/adaptation studies in the various regions and sectors.

\section{III.3 Some Implications for future NCA scenarios}

Published reviews or previous assessments (e.g., Morgan et al., 2005, MacCracken 2000) and research for this whitepaper point to six key issues that should be addressed to improve provision and application of scenarios for use in the NCA 2013 report and ongoing distributed analyses and assessments:

1. Being clear about the types of scenarios (and relationships between different types) and information that is needed and will actually be used, which will be a function of the credibility, salience, and legitimacy of these materials to both intermediate and end users (as well as other issues below, especially including making scenarios available early enough in the process to be useful);

2. Balancing centralized/decentralized scenario development in a manner that allows for coordinated guidance but also flexibility and adaptive learning on the part of participants in sectors and localities across the country

3. Making scenarios available in a timely fashion to participants in the assessment process;

4. Improving characterization and communication of uncertainty in scenarios used in the assessment process, which is partly a function of relying on many sources of information (not just one or two models) for developing descriptions of future regional changes in climate and other conditions;

5. Developing tools and capacity that facilitate participatory use of scenarios by end users in the sustained NCA process;

6. Taking advantage of already constructed scenarios and literature reviews and conducting new scenario analyses, storylines, case studies, and research as needed to fill gaps.

We offer elaboration on a few of these points below.

Coupling of scenario types: users seemed to have difficulty in relating climate, ecosystems, and socioeconomic analyses and the interactions between them within each of the regions 
and sectors. There was some coupling of climate-ecosystems/physical (hydrology) models but little coupling of climate and socioeconomic models; for example, Integrated Assessment Models (which couple all three domains) were very rarely used. It is crucial to address the relationships and consistency across different types of scenarios. Collaboration across distinct research and user communities engaged in scenario development and application is improving (see Moss et al, 2010), but there are still limits to the extent to which absolute consistency can be established across emissions, climate, ecosystem, and socioeconomic scenarios. A clear explanation of the degree of coupling across these domains needs to be incorporated into explanatory materials that accompany the scenarios.

Balance of centralized and participatory scenario processes: the decentralized and participatory approach to scenario development was not well coordinated with centralized guidance regarding scenarios. For the next report, it will be very important to be clear about the balance between use of centrally provided scenarios and regional/sectoral initiative in defining scenarios. At one end of the spectrum, the NCA could provide basic tutorials and guidance on assessment objectives and methods and strategies for thinking about the future and leave it up to regional and sectoral assessment teams to develop their own scenarios. At the other, the NCA could attempt to require use of centrally-provided data and narratives. A key issue is maintaining comparability but allowing groups latitude to develop scenarios that have credibility and salience to key issues they identify.

Stakeholder engagement with scenarios: for the most part (and with some exceptions in different regions and sectors) stakeholder involvement in the scenario process was mainly at the beginning of the process (framing) and its conclusion (reviewing analyses for validity or simply receiving the report), but rarely in the scenario development and analysis. Most involvement centered on identification of key issue areas of concern to evaluate under future climates. Fewer analyses focused on formally asking stakeholders about perceived vulnerabilities and adaptation strategies, and even fewer included stakeholders in envisioning alternative futures. Improving engagement of stakeholders in other aspects of the assessment process will be crucial for building a sustained, ongoing process.

Supporting assessment of mitigation as well as adaptation responses: mitigation was not considered as part of the previous assessments, but post-evaluations suggested that it should have been. This is important for providing resources for localities interested in assessing the full range of responses and developing climate change action plans, which need to be based on inventories and projections of human and natural emissions sources, among other factors.

\section{Needed products for NCA 2013}

In section I.2, the whitepaper differentiated "intermediate users" and "end users." These are, of course, general categories and within each, there are a number of specialized applications and needs that can be identified. For the purposes of discussion, however, the distinction is helpful in identifying broad sets of scenarios and scenario-based products 
that could be useful (and used). These include: (1) scenarios for intermediate users, especially to support and coordinate modeling and synthesis; and (2) scenarios and related tools intended to inform or support participatory processes and consideration of the implications of climate change in a range of decision and deliberative settings. There is some overlap in these two sets of needs, but there are also important tensions. For example, the former set of needs would benefit from consistent scenarios, whereas the latter set would benefit from a diversity of scenarios that take into account potential surprises (EEA, 2009). Thus, a difficult challenge for the NCA will be meeting the needs of both sets of users.

\section{IV.1 Needs identified in the NCA Workshop on Planning Regional and Sectoral Assessments}

A workshop on regional and sectoral assessments held in November 2010 involved stakeholders and researchers in identifying information needs and options for conducting these assessments. Many participants expressed support for using regions roughly analogous to those used in the 2009 report, with adjustments to follow state boundaries wherever possible. There were some suggestions for new regions, such as the Arctic. A strong desire was expressed for both understanding regional climatology and having the capacity to project conditions at the regional level at multiple time scales, including seasonal to interannual, decadal, and 50-100 years. Breakout groups identified a large number of potential sectors for consideration. Many participants sought increased emphasis on certain topics, such as the oceans, vulnerable communities, and societal responses to climate change. A dominant theme expressed the workshop was the importance of framing climate change within a multiple stressor context.

One of the most important insights was the need to focus on cross-cutting themes that integrate regional and sectoral issues and increase the applicability and usefulness of the Assessment process and products. For example, several participants identified the nexus of water, energy, and agriculture in the Southwest, the unique challenges facing urban areas (e.g., transportation, infrastructure, and public health), and oceans as important crosscutting topics for the NCA. It was also strongly suggested that in addition to emphasizing analyses across regions and sectors, it would be helpful to have deliberate overlap and interaction between regional and sectoral author teams and chapters.

Which regional definitions, sectors and cross-cutting topics are emphasized in the final outline approved for the NCA 2013 report will have implications for the scenarios needed for the Assessment. Several overarching messages emerged from the workshop regarding potential needs for and uses of scenarios. These insights are related below to the needs of intermediate and end users of the NCA.

Intermediate users

Insights from the workshop include the need for: 
- Explicitly discussing the modeling metrics and uncertainties that are incorporated into the various scenarios, and how the models perform ;

- Considering other ongoing assessment activities occurring within states and international contexts that might provide useful knowledge for how to guide the scenario development and application process (e.g., consideration of the climate atlas that will be produced for IPCC AR5 and how the scenarios and scenario products will connect with/build from this atlas approach, as well as datasets, tools, and scenario development processes that have been constructed for various state assessments that might help guide the national process and avoid 'reinventing the wheel');

- Establishing some level of scenario consistency (e.g., a suite of climate and socioeconomic scenarios used to inform emissions, impacts, vulnerability and adaptation scenarios), particularly at the higher spatial scales, with flexibility to capture context-specific nuances at regional and local scales; and

- Evaluating early on in the assessment process whether intermediate user demand exists for very fine scale projections for all regions and sectors (e.g., socioeconomic projections at the county level), and when these projections are demanded, providing clear centralized guidance for how or when to use them.

End users

Insights from the workshop include the need for:

- Making the report itself more accessible and illustrative for the end user to see the bigger picture related to the synergies, tradeoffs, and maladaptations associated with impacts, vulnerabilities, adaptation, and mitigation (perhaps by structuring the report to reflect the scenario development process itself - walking through a handful of important sectors, one-by-one, starting with narratives and storylines, and carrying these through the rest of the report); and

- Making the products useable and available online, through such means as GIS files and decision support tools.

\section{2 Options for scenarios and related products}

This section of the whitepaper identifies four broad potential sets of scenario tools/products that could be developed to meet the needs of both intermediate and end users:

- Socioeconomic narratives (qualitative descriptions of the future) and scenarios (related quantification) to explore issues in mitigation and adaptation

- Climate "outlooks" (expert-opinion-based descriptions of what is known about the evolution of climate variability and change at regional scales, drawing on a range of model outputs, observational records, and process research)

- Quantitative scenarios of climate change, changes in environmental conditions (e.g., land use, sea level, water availability/quality, and air quality), and socioeconomic conditions (mentioned above) 
- Scenario-based decision support tools (such as visualization, simulation, gaming, decision theater, and other interactive approaches for relating potential climate and socioeconomic changes to stakeholder-driven decision processes)

To the greatest extent possible, the NCA will have to make use of already developed scenarios and data sets, and coordinate with other organizations and activities to jointly develop scenarios that can serve multiple purposes. The whitepaper includes information on ongoing activities in the IPCC, other organizations, and the research community that could provide sources of data and scenarios. This leveraging approach will contribute to more timely delivery of scenarios and related products and make effective use of resources in the research community.

\section{IV.2.i Socioeconomic narratives and scenarios}

It is now widely recognized that vulnerabilities to climate change depend on more than altered patterns of precipitation, temperature, or extreme events. They also depend on where people are and where they are going (demography), what they are doing (economic patterns and changes), how they govern commerce and mobilize for action (institutions), what cultural values and social constraints exist, and what their tools are for coping (e.g., technologies, planning, and social networks). Without being able to think systematically about the future evolution of these socioeconomic conditions it is difficult to assess what future climate changes would mean for regions, sectors, and societies, especially in the longer-term. Moreover, without narratives of such dimensions of the future as starting points, it is difficult to create internally consistent scenarios of driving forces for projections of greenhouse emissions.

As mentioned in the definitions section of the whitepaper, narratives are qualitative descriptions of political, economic, institutional, cultural, and other factors that influence aspects of the future. They are useful as a foundation for quantitative scenarios and to consider the effects of factors such as institutional arrangements (e.g., laws and organizations) that cannot be quantified. Historical and analytic approaches can be used to systematically develop narratives that are rigorous and research-based to the explore evolution of important environmental and socioeconomic processes. Narratives can be used to convey the overall logic of a set of scenarios to a variety of audiences (in this sense, they are sometimes referred to as "storylines"), and can be used as the basis for quantitative scenarios, as in the IPCC SRES (Nakicenovic et al., 2000). They can also facilitate coordination across spatial scales and substantive domains (see Zurek and Hendrichs, 2007, and NRC, 2010). Some narratives are normative and explicitly explore value-based desired end-points such as "sustainable futures" while others are primarily descriptive and explore the implications of different trends and choices as they extend into the future.

Developing socioeconomic scenarios to accompany climate change scenarios over periods of many decades has, however, been difficult - partly because changes in human societies 
over long periods can be complex and profound. As a result, the socioeconomic sciences generally avoid projections that extend beyond a few decades.

Narratives could be developed for the NCA to frame assumptions about international and national developments that have consequences for vulnerability, resilience, adaptation, and mitigation in different regions, sectors, or jurisdictions of the country. For example, narratives could be developed to provide a framework for analysis of the implications of different approaches to national climate policy or different levels/types of economic growth across jurisdictions, regions, or sectors. Precedents for such cross-scale narrative frameworks that link adaptation and mitigation have been developed and, to some extent, tested (see for example, Sheppard et al., 2011). It is crucial to be realistic about what can be produced on different timescales, however. For the June 2013 NCA report, it may only be possible to provide already available narrative materials that might help to frame impact assessments, such as those developed by the National Park Service for the purposes of considering the implications of changes in climate and socioeconomic conditions on specific parks and facilities. Another option is to ask sectoral and regional assessment teams to develop narratives that focus on their priority issues or attributes. For this option to be viable, it would be necessary to provide technical guidelines and facilitation. For the longer-term sustained national assessment infrastructure, it may be possible to develop a study to produce socioeconomic narratives to accompany climate change projections as a basis for assessing regional, sectoral, and societal impacts in the U.S. (perhaps under the auspices of USGCRP, including multi-agency and stakeholder consultations).

There are a number of recent and ongoing activities on which to build. To explore what might be possible in socioeconomic scenario development, NAS/NRC organized an international workshop in Washington, DC, in February 2010 that brought together a wide range of socioeconomic scientists and climate change modelers and analysts (NRC 2010). Besides considering prospects for relatively long-term quantitative projections of such variables as demographic and economic change, the workshop considered such alternative approaches as qualitative socioeconomic narratives, as in the case of the Millennium Ecosystem Assessment.

IPCC Working Groups II and III are developing guidance to chapter authors about socioeconomic contexts for their assessments of both impact and mitigation prospects. To support this process and catalyze development of socioeconomic scenarios by the research community, an IPCC Expert Meeting on Socioeconomic Scenarios was organized November 1-3, 2010, in Berlin. The workshop continued the exploration of socioeconomic narrative/scenario development started at the NAS/NRC workshop. It included, as starting points, two "whitepapers" proposing different frameworks for developing socioeconomic narratives (Kriegler et al., 2010; vanVuuren et al., 2010). The meeting produced an agreement to develop a small number of "Shared Socioeconomic Pathways," (SSPs)_associated with supporting quantitative scenarios where possible, related to major non-climate driving forces for development paths. These SSPs will then be matched with climate scenarios to support impacts, adaptation, and vulnerability assessments. 


\section{$\underline{\text { IV.2.ii Climate outlooks }}$}

The proposal for producing expert-judgment based descriptions of the possible evolution of climate conditions at the scale of 8-10 larger regions of the U.S. grows from the observation that there are many sources of information on the range of possible climate futures. While Atmosphere-Ocean General Circulation Models (AOGCMS) remain the primary source of information on the range of possible climate futures, there is an increasing array of Regional Climate Models (RCMs) and downscaling approaches that also provide insights. An important issue to consider with use of GCMs is that they are constructed to obtain a best estimate of the likeliest climate sensitivity, not the range of sensitivity - so that they may provide results that are too narrow. Processes for intercomparison of GCMs and RCMs are in place, and methods are continuing to mature. In addition, knowledge of processes shaping regional climate change is also growing and can add value to understanding how regional climates may evolve, especially when these processes are not yet incorporated adequately into AOGCMs or RCMs, for example because they occur at scales finer than the computational grid of the models. Finally, observations of recent conditions and changes in climate are an additional valuable source of information.

No model-based method is available for integrating these four sources of information (i.e., GCMs, downscaling approaches, process knowledge, and observations), hence it is proposed that for the NCA, expert panels would draw information together focusing on both a common set of variables across regions (starting with agreed temperature and precipitation variables) as well as on topics or processes of special interest within each region. Including representatives of regionally-significant user communities and/or boundary organizations in the process would help ensure that the information produced addresses key questions and climate features. This approach would facilitate nuanced expert assessment of key processes and features important to climate in each region. The outlooks would be presented as opening sections of each regional (and if relevant, sectoral) chapter of the NCA 2013 report. In addition, if possible, the climate outlooks should provide insights for regional users into appropriate model runs and scenarios for analysis within each region. This could be a particularly valuable function of the outlooks if, as seems likely, some earlier climate model runs will need to be used in some regional or sectoral analyses because new model runs are not yet available. The outlooks would provide a means for the expert community to provide information to users on differences and the implications of new information just being made available for earlier sets of scenarios. Uncertainty is a key issue, and the type of uncertainty changes over time and over spatial scale. Natural variability dominates on short timescales $(<10 \mathrm{yrs})$ but intermodel and emissions uncertainty become more important farther out into the future (Hawkins \& Sutton, 2009, 2010). The construction of scenarios - and the choices about models to include and how to include them, in order to quantify uncertainty - therefore depends partly on the timescale of relevance. Information to guide users through this thicket of issues would be extremely valuable for ongoing distributed assessment activities. 
The outlooks should include maps and figures. A number of effective presentations based on downscaling results were used in NCA 2009, and in addition there are relatively simple graphical approaches that can be used to portray the spread of model results for key variables and to compare projections to current levels of climate variability that stakeholders and managers already have experienced in practice (e.g., see Figure 3, from Ruosteenoja et al., 2003). Key issues in preparing the outlooks are rapidly establishing a regionally-based expert judgment process and providing some common information and assumptions about future global-scale changes on which the regional outlook groups could base their assessment. As a fallback, the NCA could simply make the data sets available to regional and sectoral teams, but prior experience in the NCA 2000 and 2009 indicates that this will reduce use of the scenarios.

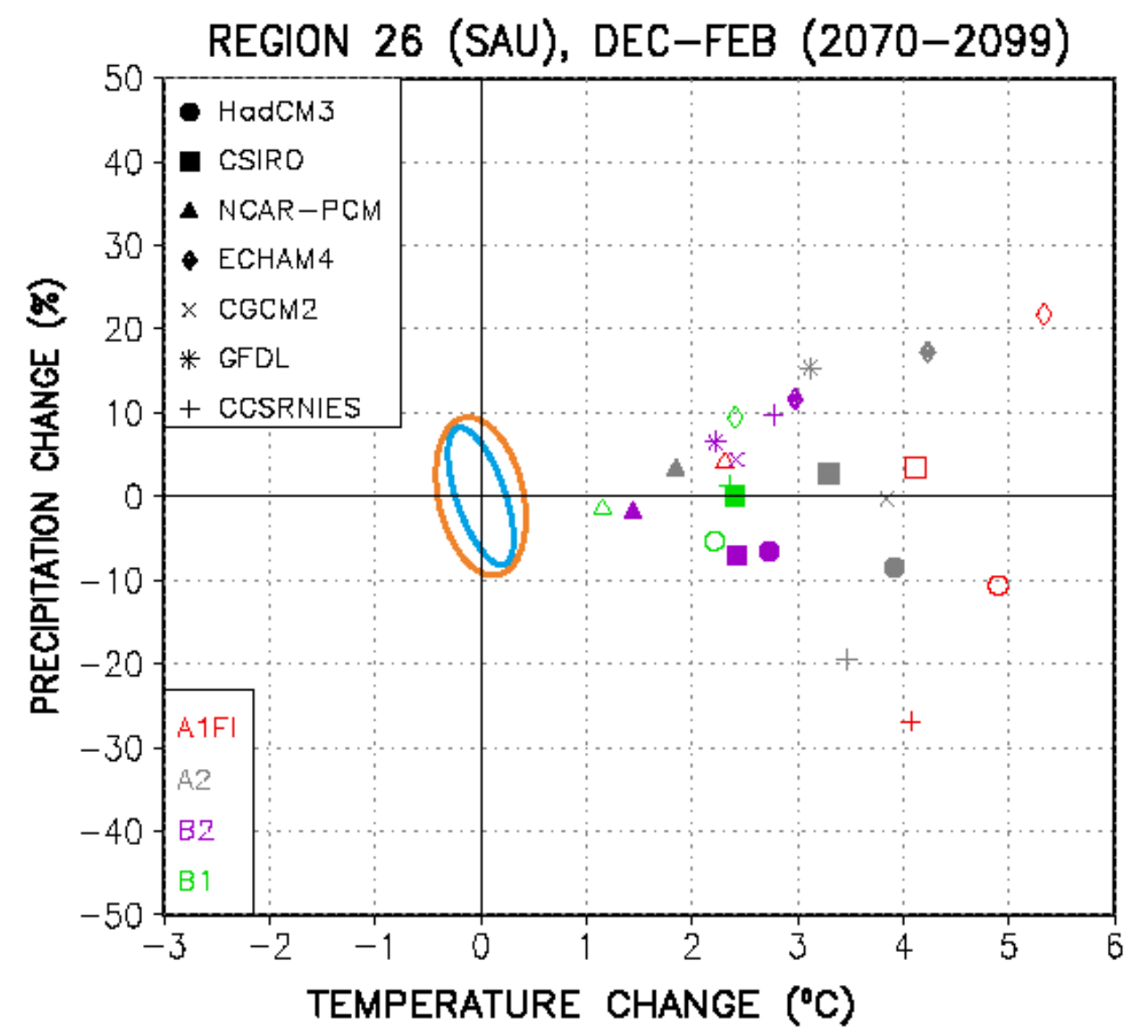

Source: Ruosteenoja et al., 2003

Figure 3: Scatterplot showing multiple model results (keyed to different symbols in the upper left-hand corner of the plot) for temperature and precipitation change for Southern Australia based on runs forced with different SRES emissions scenarios (different colors keyed to scenarios in lower left corner of plot), related to model estimates of variability (colored ovals). Such scatter plots are frequently developed to display seasonal information.

IV.2.iii Integrated sets of quantitative scenarios of climate, environmental, and $\underline{\text { socioeconomic conditions }}$ 
The standard method for development and application of scenarios in climate research by intermediate users is quantitative data sets of model outputs produced by one set of models and provided to others as inputs. Approaches for these inter-model and research community transfers have been refined with experience. Researchers from the integrated assessment, climate, and impacts research communities have established a new process for coordinating the handoff of scenario information called the "parallel process" to improve cross-community interactions (Moss et al., 2010). This new process is likely to affect the options for producing the scenarios for the NCA. The process replaces a sequential approach in which detailed socioeconomic narratives and scenarios were prepared first to develop projections of emissions, which were then provided to climate models to produce climate scenarios, which were eventually provided for impacts, vulnerability, and adaptation research. The sequential process took many years to complete, resulting in inconsistencies, and the socioeconomic scenarios that started the process were usually focused primarily on energy supply/emissions projection. The parallel process reorganizes these inter-community transfers by starting from radiative forcing and developing detailed socioeconomic scenarios and climate scenarios at the same time (see Figure 4). This is enabling development of socioeconomic scenarios that address key uncertainties in factors that affect impacts, adaptation, and vulnerability, as well as those that influence emissions, as has historically been the case.

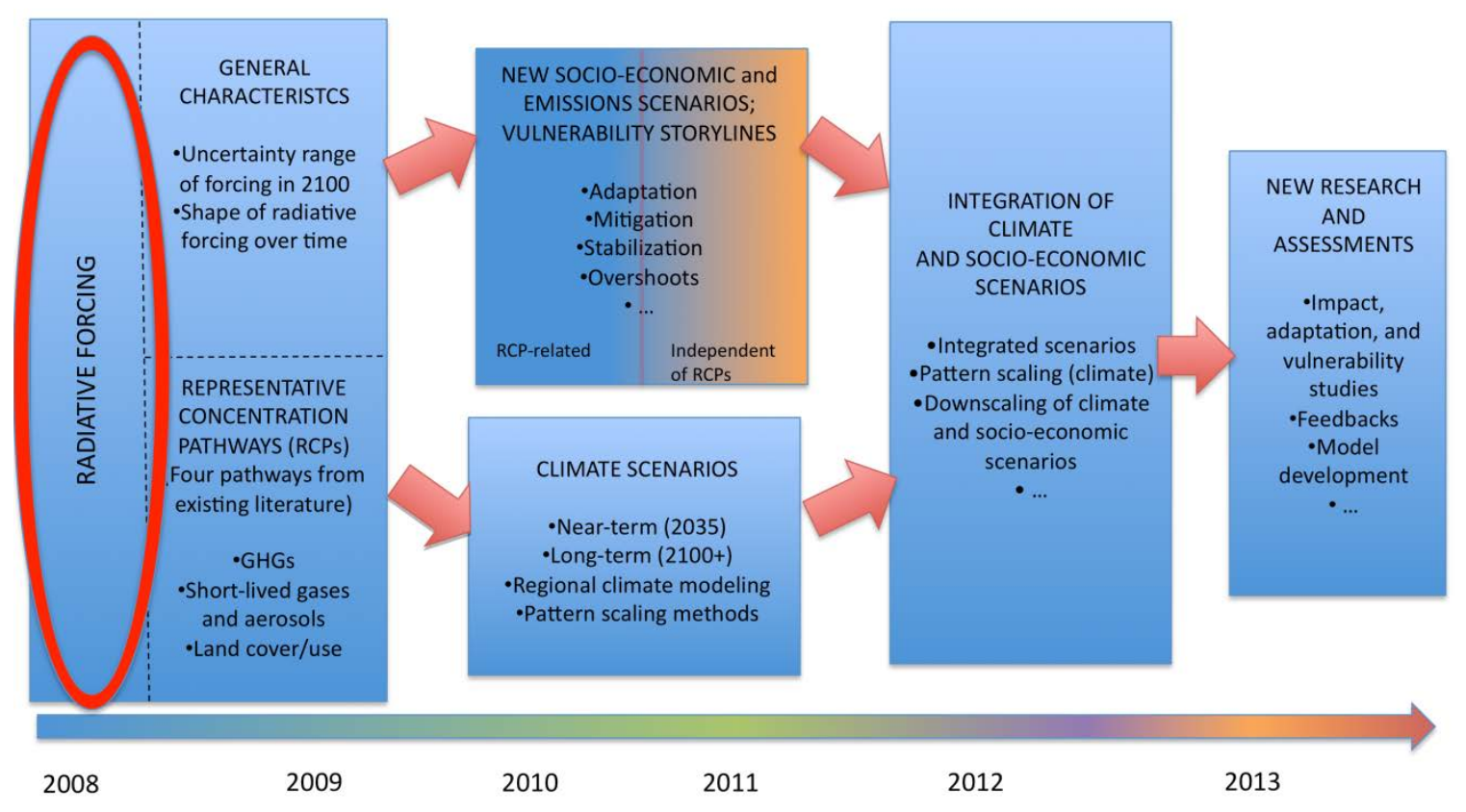

Source: Moss et al., 2010 
Figure 4: "Parallel process" for exchanging data and information across different research communities involved in climate change research and assessment. General characteristics of radiative forcing (concentrations of GHG and other forcing agents over time) depicted in "Representative Concentration Pathways" (RCPs) are used in climate model experiments (organized under the auspices of CMIP5) and efforts to develop new socioeconomic scenarios (organized by a new Integrated Assessment Modeling Consortium, the IAMC, and by researchers who research impacts, adaptation, and vulnerability). The new process provides more time to develop socioeconomic scenarios that are conceptualized and developed to address questions related to both adaptation and mitigation. The new process is based on the observation that many different socioeconomic development pathways can be associated with any given radiative forcing trajectory. Many research issues and needs have been created by the new process.

Ongoing efforts are focusing on climate model experiments using the RCPs (coordinated by CMIP5) and development of socioeconomic scenarios (see NRC, 2010 and http://www.ipcc-wg3.de/meetings/expert-meetings-and-workshops/WoSES). Within the context of the parallel process, a great deal of effort has been put into ensuring that emissions and land use data associated with the "Representative Concentration Pathways" (RCPs) were prepared and presented in a form readily useable by climate modeling groups (see the so-called "hand-shake document" describing data provided by integrated assessment modeling teams for use in climate modeling, van Vuuren. et al., 2008). Steps are needed to ensure that climate and socioeconomic scenarios are readily accessible to the impacts, adaptation, and vulnerability research community-an issue of great importance to the NCA in both the immediate context of NCA 2013 and the sustained distributed assessment process.

This section of the whitepaper focuses on potential needs and sources of data from different types of climate models and downscaling methods. Additional information on sources of data for environmental and socioeconomic scenarios will also need to be developed. The section draws heavily on an inventory of approaches to climate modeling and downscaling prepared for the Piloting Utility Modeling Applications for climate change (PUMA) workshop.

\section{Quantitative climate scenarios and downscaling}

There is an increasingly sophisticated array of tools for developing regional climate change information for different uses, including GCMs, RCMs (a.k.a. dynamical downscaling), statistical downscaling, and historical climatologies. The data needs vary from use to use, as does the suitability of the techniques for discrete applications. A number of inventories of variables from climate model experiments needed for different types of impacts models have been prepared and are available (see, for example, TGICA 2007 for a list of variables requested by the impacts, adaptation, and vulnerability research community, and PCMDI 2010 for the full list provided in the CMIP5 archive). This draft of the whitepaper does not catalogue or prioritize across these needs because it is assumed that these needs go beyond developing contextual information and are related to modeling and other forms of quantitative analysis. 
It is crucial to establish realistic objectives regarding provision and use of quantitative scenario information, especially in the context of NCA 2013. It may be the case that most of the quantitative information that is developed will be more useful to distributed assessments in regions and sectors, and thus to a future snapshot of this activity in NCA 2017 (assuming the periodicity of assessments established in the GCRA is maintained).

A whitepaper inventorying the status and availability of data from a number of current climate modeling and downscaling efforts has been prepared for the PUMA project (Sharp, 2010). One of the major objectives of PUMA is to identify state-of-the-art climate modeling tools and techniques for use by a select group of Water Utility Climate Alliance members committed to being technically prepared to conduct climate impacts assessments for their systems. These members have both water supply and stormwater management interests. The PUMA workshop products include a report from the meeting held in San Francisco from 1-3 December 2010. Organizers of the PUMA workshop have made the text of the whitepaper inventory of climate modeling activities available to participants in the NCA scenarios workshop (see document titled "An Inventory of Approaches to Climate Modeling and Downscaling" on the scenarios workshop website). The paper reviews the status of recent and current GCM intercomparisons, including CMIP3 and CMIP5, as well as the North American Climate Change Assessment Program (NARCCAP) and the Regional Climate Prediction Dot Net project. It also reviews the status of selected downscaling efforts. Summary tables are provided; the overall summary table is produced below (see Figures 5 and 6).

\begin{tabular}{|c|c|c|c|c|}
\hline & \multicolumn{4}{|c|}{ Modeling Project } \\
\hline & CMIP3 & CMIP5 & NARCCAP & RegCPDN \\
\hline $\begin{array}{l}\text { Approximate } \\
\text { Resolution (degrees } \\
\text { unless noted) }\end{array}$ & $\begin{array}{l}\text { Atmos: } 1.1 \times 1.1- \\
4.0 \times 5.0 \\
\text { Ocean: } 0.2 \times 0.3- \\
4.0 \times 5.0\end{array}$ & $\begin{array}{l}\text { native model } \\
\text { resolution; } \\
\text { details TBD }\end{array}$ & $50 \mathrm{KM}$ & $\begin{array}{l}25 \times 25 \mathrm{KM} \\
\text { (atmos only) }\end{array}$ \\
\hline $\begin{array}{l}\text { Output Timestep(s) } \\
\text { Frequency }\end{array}$ & $\begin{array}{l}3 \text { hrly; mon/daily } \\
\text { mean; extreme }\end{array}$ & $\begin{array}{l}3 / 6 \text { hrly; mon/ } \\
\text { daily/annual } \\
\text { mean }\end{array}$ & 3 hrly; daily & $\begin{array}{l}\text { daily; monthly } \\
\text { means; count }\end{array}$ \\
\hline Domain & global & global & North America & Western US \\
\hline \# Models & 23 & TBD & $\begin{array}{l}\text { Regional = 6; } \\
\text { Global = } 4 \text { (not } \\
\text { incl. NCEP); } 20 \\
\text { combo's } \\
\text { planned }\end{array}$ & $\begin{array}{l}\text { (1) Regional/ } \\
\text { Global pairing - } \\
\text { HadRM3P/ } \\
\text { HadAM3P }\end{array}$ \\
\hline \# Output Params & $118^{a}$ & $404^{b}$ & 49 & 50 \\
\hline $\begin{array}{l}\text { SRES/RCP } \\
\text { Emissions Scenarios }\end{array}$ & (3) $A 2, A 1 B, B 1$ & $\begin{array}{l}\text { (4) RCP's 2.6, } \\
4.5,6,8.5\end{array}$ & (1) $\mathrm{A} 2$ & (2) A1B, B1 \\
\hline $\begin{array}{l}\text { Time Periods } \\
\text { Covered }\end{array}$ & $\begin{array}{l}1850-2000 \\
2000-2100 \\
2000-2300\end{array}$ & $850-2300^{c}$ & $\begin{array}{l}1980-2004 \\
1971-2000 \\
2041-2070\end{array}$ & $\begin{array}{l}\text { 1959-2010; } \\
\text { 2010-2100 } \\
\text { planned }\end{array}$ \\
\hline Notes & $\begin{array}{l}\text { basis for IPCC } \\
\text { AR4 }(2007)\end{array}$ & $\begin{array}{l}\text { basis for IPCC } \\
\text { AR5 (due late } \\
\text { 2013) }\end{array}$ & & \\
\hline
\end{tabular}

a"High Priority Output" only; only ocean and atmosphere available b"Priority 1" output only; ocean, land, and atmosphere available cRange dependent on exactly which Tier 1 and Tier 2 experiments are selected dFor example, Number of days with Tmax $>30$ degC 
Source: Sharp-PUMA inventory (2010)

Figure 5: Summary of recent and ongoing model projects prepared for Piloting Utility Modeling Applications for climate change workshop.

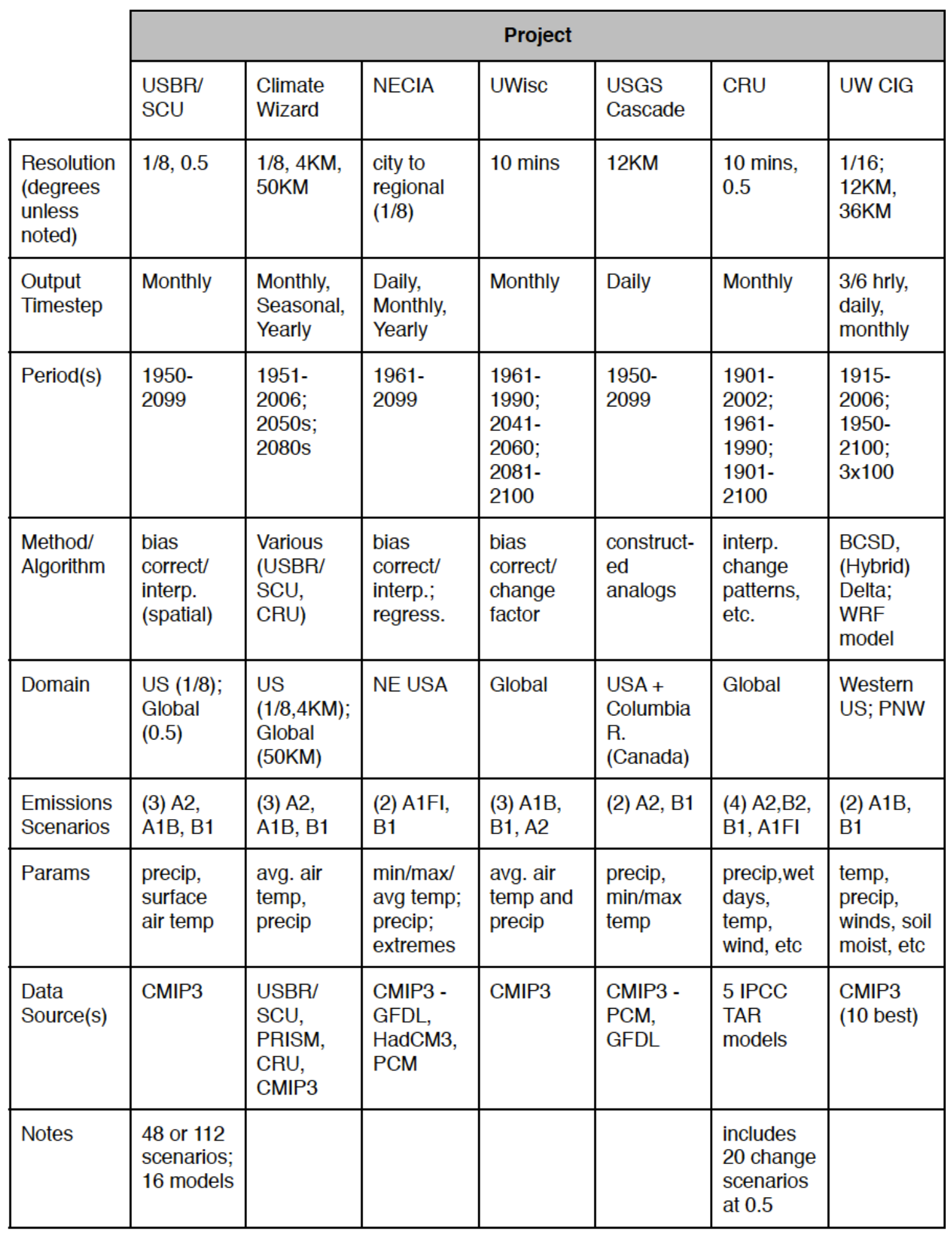

Source: Sharp-PUMA inventory (2010) 
Figure 6: Selected downscaling projects from the Piloting Utility Modeling Applications for climate change workshop.

In addition to quantitative climate scenarios and downscaling, quantitative scenarios of key environmental conditions such as land use and sea level rise will also be needed. Projection of environmental conditions sensitive to climate variables are developed using climate scenarios and data, and also serve as inputs to a wide range of quantitative and qualitative research and assessments that evaluate implications for human activities and infrastructure. For example, air quality is affected by anthropogenic emissions of a variety of pollutants and atmospheric processes sensitive to temperature and other conditions, and a variety of models use climate scenarios as inputs to model chemistry and circulation processes that affect air quality and incidence of air pollution events. Models of vectors of a range of diseases use climate scenarios inputs and provide information used in assessment of human health impacts. Sea level rise projections depend on a range of climate sensitive processes and are used as inputs into studies of coastal erosion and flooding. Models of changes in outputs of different crops require climate scenarios and provide inputs to agricultural trade models that produce information on the potential impacts of climate change on agricultural prices and food security.

Quantitative environmental scenarios that examine the implications of climate change for human activities and well being are becoming more sophisticated. Efforts at intercomparing different realizations of models within related classes used to produce this information are still in the early stages, however. A current example of intercomparison activities is the Agricultural Model Intercomparison and Improvement Project (AgMIP) (reference and website under development). This is a distributed simulation exercise that will compare results across models for both historical and projected future climate change conditions with participation of multiple crop and world agricultural trade modeling groups. AgMIP will provide a multi-scale impact assessment using current methods for climate and agricultural scenario generation. Scenarios and modeling protocols will be distributed on the web, and multi-model results will be collated across crops and regions. Intercomparison of other types of environmental models and scenarios is needed in the longer-term and may provide useful inputs to distributed assessment activities (see Figure 7). 


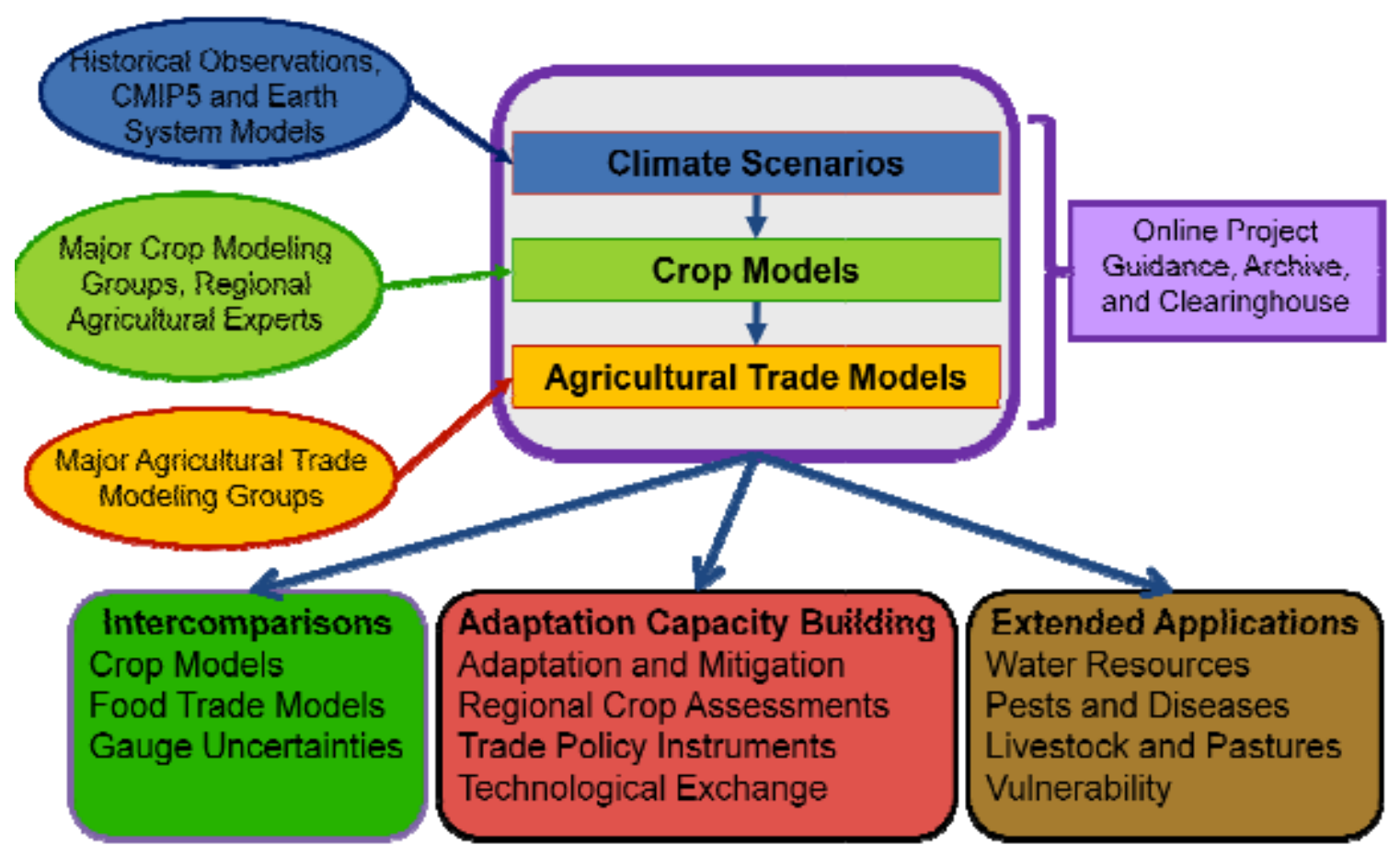

Source: Alex Ruane and Cynthia Rosenzweig

Figure 7: Conceptual framework of AgMIP project depicting flow of scenario information from climate change, to environmental conditions and outputs, to models of human activity and impact,

\section{IV.2.iv Scenario tools to support participatory processes}

Most global or national scale assessments are expert-driven, and as a consequence, scenarios developed to support these assessments have primarily been quantitative and used to coordinate different areas of modeling and evaluation by providing shared input assumptions. As mentioned above, however, there are significant benefits for end-users participating in scenario development. There is growing experience, with participatory assessment approaches in which a mix of stakeholders and experts engage in a shared assessment process (NRC, 2009; Salter et al., 2010). A participatory process is a purposefully designed set of activities structured around framing (including clarifying objectives and identifying participants), a set of participatory activities that can include workshops and engagement of participants through other means such as social media or technology such as decision theaters, and a set of outcomes that could be a decision, a community plan, a report, films/audios, or other forms of knowledge sharing or exchange.

Participatory processes for complex planning and decisionmaking have been developed over several decades in response to shortcomings of purely expert-based decision support (Arnstein, 1969; Fischer, 1993). These processes enhance understanding and build community capacity for making informed decisions that can integrate scientific research and local knowledge. Participatory processes can enable participants to clarify different perspectives about potential impacts and response options, and build acceptance and ownership of agreed actions. But they also have costs, including requiring additional time 
and resources, and being more difficult to control with respect to focus or outcome. Research that inventories and evaluates approaches to development and use of scenarios in participatory processes for the context of the NCA is currently being prepared (Wiek et al., in preparation). This section of the whitepaper draws on this draft evaluation and briefly introduces several options and ideas for next steps.

The primary purpose of participatory processes has been the exchange or production of knowledge across different groups of experts and stakeholders (Wiek et al., 2006). Following early categorizations, participation can range from information (communicating from experts to stakeholders) and consultation (eliciting from stakeholders to experts), to collaboration (mutual interaction, co-production). Standardized forms of engagement that correspond to these three categories are, for instance, expert hearings/input (information), stakeholder focus groups (consultation), and workshops (collaboration).

Participatory scenario studies on climate change develop or use the full spectrum of scenarios, from socio-economic drivers and emissions to impacts and responses (Wiek et al., in preparation). Shaw et al. (2009), Loibl et al. (2010), Bryan et al. (2011) are three illustrative examples of how participatory scenario studies engage scientists and stakeholders in the development or use of climate change scenarios to anticipate local climate-change impacts and explore response options. Climate and socioeconomic scenarios are developed and used in these processes in a variety of ways that enable participants to evaluate how local decision options that may be affected by changes in climate (e.g., related to community economic development, infrastructure, land use, investment in renewable energy technologies, etc.) perform under a range of potential future climate (and socioeconomic) conditions. In this sense, the ultimate purpose of many participatory scenario exercises is to help decisionmakers to broaden the range of policies under consideration and to help choose among these policies.

However, the specificity needed in the participatory scenarios to develop this wider range of policy choices for decisionmakers might not be achievable across all regions and sectors for the 2013 NCA. That is, at higher levels of aggregation, there are likely too many variables and competing interests to effectively evaluate context specific policy options. To address this limitation, the 2013 NCA might consider supporting several case studies that highlight this potential use of participatory scenarios, and future NCA efforts could expand upon these examples while providing the necessary information for carrying participatory scenario exercises with decisionmakers.

With advances in computer and communications technology, a new type of participation has emerged in scenario processes, namely participatory tools-first and foremost, interactive and immersive visualization tools (Salter et al., 2009). These consist of a range of visual and spatial media derived from modeling, data, scenarios, and descriptive narratives used to contextualize climate change information in two and three dimensions at the local or regional level (Sheppard et al., 2011). They go beyond conventional text and scientific charts, using specialized three-dimensional modeling software or widely available virtual globe platforms (e.g., Google Earth). Such visual tools have been shown to increase cognition (Winn, 1997), and improve the salience of information to users and 
awareness of experiential or qualitative factors (Nicholson-Cole, 2005; Sheppard, 2005). These characteristics address the need by decision-makers to assess community acceptance and feasibility of otherwise sound decisions on adaptation and policy (Burch et al., 2010).

Among the more specialized participatory tools which apply to climate change scenarios (with more or less sophisticated visual components) are (1) simulation tools that allow stakeholders to build capacity in systems thinking related to climate change drivers, impacts, and responses (e.g., Quest: Robinson, 2008) and (2) gaming tools that allow stakeholders to engage with climate change scenarios in entertaining and competition settings (Vervoort et al., 2010). Participatory tools can be integrated in participatory processes or can stand alone, for instance, as web-based or kiosk applications which engage individuals (but do not enable direct person-to-person interaction). Advantages of participatory tools compared to participatory processes are standardized presentation of information, accessibility to potentially large numbers of users, instant feedback, and low/no cost usage. The downsides are the relatively high development costs, as well as the lack of in-depth exploration, deliberation, and adaptability to stakeholder interests. When tools such as visualizations are embedded in participatory processes, as in the Local Climate Change Visioning process which integrates various types of modeling across scales within 'visual narratives' (Pond et al., 2010), deeper levels of engagement and high credibility can be achieved with both non-expert and expert end-users.

Temporary and permanent facilities have been established to engage stakeholders in the development and use of climate change scenarios. Museum exhibitions, such as the recent exhibition on "Rising Currents" in the Museum of Modern Art in New York, provide temporary opportunities for stakeholders to explore climate impacts and response options to climate change. Compared to participatory tools, museum settings have the advantage that they allow for alternative forms of information presentation, such as large installations, dioramas, multi-media, experiential settings, etc. They also provide the flexibility to combine different forms of participatory tools and processes. "Decision theaters" have also been designed to support participatory scenario-development and decision-making related to climate change, on an ongoing basis. Using participatory tools and processes, in particular visualizations, decision theaters are both physical spaces in which the participatory process occurs and virtual spaces for decision support and evaluation research. More than a visualization production studio, decision theaters offer the advantage of a research laboratory (control, documentation, etc.), a resource for multiple end-users to access standardized scenario data-sets, and a hub for training in best practices (Sheppard, 2006); but there are also disadvantages such as limited geographical accessibility, high maintenance cost, and required technical expertise. Permanent decision theaters are in operation or under construction at locations including Arizona State University, the University of British Columbia (Canada), University of East Anglia (UK), Linköping University (Sweden), and Huazhong University (China). An international research network among the decision theaters has been initiated.

This is a good foundation for expansion of the participatory use of scenarios in climate assessment. NCA 2013 could start by identifying and evaluating initial applications of 
scenarios in participatory processes with a shared, structured framework that allows a comparison of framing, participatory activities, and outcomes; for example with respect to success in engaging stakeholders from different regions and developing/using different scenarios to build and communicate knowledge. In the longer-term, there are a number of tools and processes that the NCA could advance; for example:

- A handbook that offers information on a range of participatory approaches for constructing and using climate change scenarios (with empirical illustrations and case studies as templates for "good practice") and spells out their key features, strengths, and weaknesses (comparison and evaluation);

- A database with empirical participatory scenario case studies to provide a growing knowledge base and model projects for experts and stakeholder groups;

- A website that provides key information on participatory scenario approaches (short version of the Handbook) and provides interactive exchange and research coordination (forum, blog, updating of the database, etc.); and

- Coaching and training workshops to build capacity in applying participatory scenario approaches.

\section{Final Thoughts: Preparing for NCA 2013 and Ongoing Assessments}

The NCADAC will need to address a number of crucial questions quickly if scenarios and related tools, methods, and resources for users and participants are to be developed in time for the 2013 Report.

How will scenarios be used by different sets of users in the NCA? The assessment is more likely to succeed in its objectives if there is a strategy for preparing and applying scenarios. This strategy needs to be guided by the structure of the NCA 2013 report and plans for the long-term process. The structure of the report needs to inform decisions regarding time frames, spatial scale, uncertainties to be addressed in the scenarios, and technical guidelines for their use by the sectoral and regional assessment teams. The strategy needs to specify what products are required, who will use them, and how, so that materials can be prepared in a timely and appropriate fashion.

Support for implementation of the scenario strategy and monitoring progress throughout the process will also increase the likelihood that objectives are met. This could include providing facilitation to regional and sectoral teams.

The NCADAC should consider establishing a scenario working group composed of members of the research community and users to develop a detailed strategy for its approval. This working group could also provide support for users and monitor implementation. In addition, consideration should also be given to documenting and evaluating the entire scenario process for improvement of future assessments. The working group could assist in designing an evaluation plan.

What scenario products to support the assessment should be prioritized? The four sets of products identified in the whitepaper constitute a good initial set of options for the 
assessment. These include: (1) socioeconomic narratives; (2) climate "outlooks"; (3) quantitative scenarios of emissions, climate, environmental conditions; and (4) tools and processes to support use of scenarios in distributed assessments. These materials and resources would provide both a degree of coordination across the assessment and facilitate communication and stakeholder engagement to develop decision-support oriented scenarios for the regions and sectors. Many detailed questions remain about the specific attributes of these products, including:

- What are the desired attributes of climate information that matter most? What timescales should be addressed? What variables are most needed? What are the most accessible and appropriate sources for these scenarios?

- What are the characteristics of needed socioeconomic and/or qualitative scenarios (e.g., future socioeconomic development pathways including such things as population projections, GDP, land use, energy system evolution)? What are the sources of such information? How can scenarios be co-produced with local and regional expertise? What aspects of the future should be highlighted? What are the most relevant time frames for analysis?

- What environmental scenarios are needed (e.g., sea level rise, air quality, water quality/availability)? What are the sources for this information? How can consistency of information be ensured? How can the information be conveyed to users?

- How should uncertainty be represented in the scenarios (qualitative and quantitative options) in a manner that is transparent and useful? Can trends that are already inevitable be clearly distinguished by users from those which remain uncertain?

- What degree of consistency is needed across scenario components and how can this level of consistency be achieved?

- What technical guidelines or information can be provided to facilitate development and use of regionally- or sectorally-oriented scenarios by teams in sectors and regions, and how can regional and sectoral activities be structured to indentify priorities for tools, enhanced processes, and resources (e.g., participatory tools described above) for the long-term?

- What data/information management systems need to be developed, for example to enable various users to access materials that are prepared?

Given the limited time available for preparing the NCA 2013 report to meet the requirements of the global change research act, the NCADAC will need to find an appropriate level of ambition for the assessment strategy; one that balances wanting to provide a range of resources for participants over the short- and long-terms with the reality that time and resources are limited. The science of scenarios has advanced, and new tools and processes that facilitate application of scientific insights in deliberative and decision making processes have advanced. As evidenced in this workshop, there is great enthusiasm among the research community and end users. An option for a minimalist strategy is to select from existing resources a limited set of scenarios on future climate, environmental, and socioeconomic conditions at a regional scale to facilitate coordination; to provide technical guidelines on how to relate existing research and other sets of scenarios used in the literature to the ones identified for the NCA; and to include an 
evaluation of selected completed or ongoing participatory scenario activities in the report. Additional options with a higher level of ambition include preparation of climate change outlooks and development of a process in which regional and sectoral assessment teams prepare scenarios that are embedded in the broad regional scenarios. Implementation of even some of these options will constitute an advance over past practice and contribute to preparation of the 2013 report and development of resources to support an ongoing distributed assessment process; the key objectives of the NCA.

\section{References}

Arnstein, S. R. 1969. A ladder of citizen participation. Journal of the American Planning Association 35(4), 216-224.

Bradfield, R., G. Wright, G. Burt, G. Cairns, and K. van der Heijden. 2006. The origins and evolution of scenario techniques in long range business planning. Futures 37, 795-812.

Bryan, B., N. D. Crossman, D. King, W. S. Meyer. 2010. Landscape futures analysis: Assessing the impacts of environmental targets under alternative spatial policy options and future scenarios. Environmental Modelling \& Software 26(1), 83-91.

Burch, S, S. R. J. Sheppard, A. Shaw, and D. Flanders. 2010. Planning for climate change in a flood-prone community: Municipal barriers to policy action and the use of visualizations as decision-support tools. Journal of Flood Risk Management 3(2),126139.

Carter, T. R., E. L. la Rovere, R. N. Jones, R. Leemans, L. O. Mearns, N. Nakicenovic, A. B. Pittock, S. M. Semenov, J. Skea, S. Gromov, A. J. Jordan, S. R. Khan, A. Koukhta, I. Lorenzoni, M. Posch, A. V. Tsyban, A. Velichko, N. Zeng, S. Gupta, and M. Hulme. 2001. Developing and applying scenarios. In Climate Change 2001: Impacts, Adaptation and Vulnerability. Contribution of Working Group II to the Third Assessment Report of the Intergovernmental Panel on Climate Change, J. J. McCarthy, O. F. Canziani, N. A. Leary, D. J. Dokken, and K. S. White (Eds). Cambridge University Press, Cambridge, UK.

Climate Change Science Program (CCSP). 2003. Strategic Plan for the Climate Change Science Program. Climate Change Science Program Office, Washington, DC. http://www.climatescience.gov/Library/stratplan2003/final/default.htm

Desai, S., and M. Hulme. 2004. Does Climate Adaptation Policy Need Probabilities? Climate Policy 4:2, 107-128.

European Environment Agency (EEA). 2009. Looking back on looking forward: A review of evaluative scenario literature. Technical report no. 3/2009, Copenhagen.

Fisher, B. S., N. Nakicenovic, K. Alfsen, J. Corfee Morlot, F. de la Chesnaye, J.-Ch. Hourcade, K. Jiang, M. Kainuma, E. La Rovere, A. Matysek, A. Rana, K. Riahi, R. Richels, S. Rose, D. van Vuuren, R. Warren. 2007. Issues related to mitigation in the long term context. In Climate Change 2007: Mitigation. Contribution of Working Group III to the Fourth Assessment Report of the Inter-governmental Panel on Climate Change. B. Metz, O. R. Davidson, P. R. Bosch, R. Dave, L. A. Meyer (eds), Cambridge University Press, Cambridge, UK.

Fischer, F. 1993. Citizen participation and the democratization of policy expertise: From theoretical inquiry to practical cases. Policy Sciences 26, 165-187. 
Grubler, A. \& Nakicenovic, N. 2001. Identifying dangers in an uncertain climate. Nature 412, 15.

Hall, Jim. 2007. Probabilistic climate scenarios may misrepresent uncertainty and lead to bad adaptation decisions. Hydrol. Process. 21, 1127-1129, DOI: 10.1002/hyp.6573.

Hawkins, E. and R. Sutton. 2010. The potential to narrow uncertainty in projections of regional precipitation change. Climate Dynamics, DOI 10.1007/s00382-010-0810-6.

Hawkins \& Sutton, 2009, 'The potential to narrow uncertainty in regional climate predictions', BAMS, 90, p1095, doi: 10.1175/2009BAMS2607.1

Karl, T. R., J.M., and T. C. Peterson (eds). 2009. Global Climate Change Impacts in the United States. Cambridge University Press, Cambridge, UK.

Katz, R.W, 2002. Techniques for estimating uncertainty in climate change scenarios and impact studies. Climate Research, 20, 167-185.

Knutti, R., F. Joos, S. A. Müller, G.-K. Plattner, and T. F. Stocker. 2005. Probabilistic climate change projections for CO2 stabilization profiles. Geophys. Res. Lett., 32, L20707, doi:10.1029/2005GL023294.

Kriegler, E., B. C. O’Neill, S. Hallegatte, T. Kram, R. Lempert, R. H. Moss, T. J. Wilbanks. 2010. Socio-economic Scenario Development for Climate Change Analysis. CIRED Working Paper DT/WP No 2010-23, October 2010. Available for download at: http://www.centre-cired.fr/IMG/pdf/CIREDWP-201023.pdf

Lempert, Robert. 2010. Presentation: Philosophies and State of Science in Projecting LongTerm Socio- Economic Change: What do we know about the options and their effectiveness? Available at:

http://www7.nationalacademies.org/hdgc/Philosophies_and_State_of_Science_Present ation_by_Robert_Lempert.pdf

Loibl, W., A. Walz. 2010. Generic regional development strategies from local stakeholders' scenarios - the Montafon experience. Ecology and Society 15(3), Art. 3.

MacCracken, M. 2000. Status report and some initial thoughts on lessons learned from the first phase of the US National Assessment on the potential consequences of climate variability and change. Paper prepared for discussion at the meeting of the Committee on Global Change Research National Research Council, Washington DC, October 23-24, 2000.

MacCracken, M., E. Barron, D. Easterling, B. Felzer, and T. Karl. 2001. Chapter 1: Scenarios for climate variability and change. In Climate Change Impacts on the United States: The Potential Consequences of Climate Variability and Change, Report for the US Global Change Research Program, Cambridge University Press, Cambridge UK.

Mearns, L. O., M. Hulme, T. R. Carter, R. Leemans, M. Lal, P. Whetton, L. Hay, R. N. Jones, R. Katz, T. Kittel, J. Smith, R. Wilby L. J. Mata, J. Zillmann. 2001. Climate scenario development. In Climate Change 2001: The Scientific Basis. Contribution of Working Group I to the Third Assessment Report of the Intergovernmental Panel on Climate Change, J. T. Houghton, Y. Ding, D. J. Griggs, M. Noguer, P. J. van der Linden, X. Dai, K. Maskell, and C. A. Johnson (eds.), Cambridge University Press, Cambridge, UK and New York, NY, USA.

Melillo J., T. Janetos, D. Schimel, and T. Kittel. 2001. Chapter 2: Vegetation and biogeochemical scenarios. In Climate Change Impacts on the United States: The Potential Consequences of Climate Variability and Change, Report for the US Global Change Research Program, Cambridge University Press, Cambridge UK. 
Morgan, M. G., R. Cantor, W. C. Clark, A. Fisher, H. D. Jacoby, A. C. Janetos, A. P. Kinzig, J. Milillo, R. B. Street, and T. J. Wilbanks. 2005. Learning from the U.S. National Assessment of Climate Change Impacts. Environmental Science and Technology 39(23), 9023-9032.

Moss, R. H., J. A. Edmonds, K. A. Hibbard, M. R. Manning, S. K. Rose, D. P. van Vuuren, T. R. Carter, S. Emori, M. Kainuma, T. Kram, G. A. Meehl, J. F. B. Mitchell, N. Nakicenovic, K. Riahi, S. J. Smith, R. J. Stouffer, A. M. Thomson, J. P. Weyant, T. J. Wilbanks, 2010. The next generation of scenarios for climate change research and assessment. Nature 463 (7282), 747-756.

Nakicenovic, N., J. Alcamo, G. Davis, B. de Vries, J. Fenhann, S. Gaffin, K. Gregory, A. Grübler, T. Y. Jung, T. Kram, E. L. la Rovere, L. Michaelis, S. Mori, T. Morita, W. Pepper, H. Pitcher, L. Price, K. Riahi, A. Roehrl, H-H. Rogner, A. Sankovski, M. Schlesinger, P. Shukla, S. Smith, R. Swart, S. van Rooijen, N. Victor, Z. Dadi. 2000. Chapter 3: Scenario driving forces. In Special Report on Emissions Scenarios. Intergovernmental Panel on Climate Change, N. Nakicenovic and R. Swart (eds), Cambridge University Press, Cambridge, UK . National Assessment Synthesis Team (NAST). 2001. Climate change impacts on the United States: the potential consequences of climate variability and change. Foundation Report. Report for the U.S. Global Change Research Program. Cambridge, United Kingdom: Cambridge University Press. http://www.globalchange.gov/what-wedo/assessment/nca-reports/the-first-national-assessment-2000.

National Research Council (NRC). 2009. Informing decisions in a changing climate. Panel on Strategies and Methods for Climate-Related Decision Support. Washington, DC: The National Academies Press.

National Research Council (NRC). 2010. Describing Socioeconomic Futures for Climate Change Research and Assessment: Report of a Workshop. Panel on Socio-Economic Futures for Climate Change Research and Assessment, Committee on Human Dimensions of Global Change, Division of Behavioral and Social Sciences and Education. Washington, DC: The National Academies Press.

Nicholson-Cole, S. 2005. Representing climate change futures: A critique on the use of images for visual communication. Computers, Environment and Urban Systems 28(3), 255-273.

Parson, E. A., M. G. Morgan, A. Janetos, L. Joyce, B. Miller, R. Richels, T. Wilbanks. 2001. Chapter 3: The socioeconomic context for climate impact assessment. In Climate Change Impacts on the United States: The Potential Consequences of Climate Variability and Change, Report for the US Global Change Research Program, Cambridge University Press, Cambridge UK.

Parson, E., V. Burkett, K. Fisher-Vanden, D. Keith, L. Mearns, H. Pitcher, C. Rosenzweig, and M. Webster. 2007. Global Change Scenarios: Their Development and Use (Sub-report 2.1B of Synthesis and Assessment Product 2.1 by the US Climate Change Science Program and the Subcommittee on Global Change Research). Department of Energy, Office of Biological \& Environmental Research, Washington DC, 106.

Pittock, A.B., Jones, R.N., \& Mitchell, C.D. 2001. Probabilities will help us plan for climate change. Nature 413, 249.

Pond, E., O. Schroth, S.R.J. Sheppard, S. Muir-Owen, I. Liepa, C. Campbell, J. Salter, K. Tatebe, and D. Flanders. 2010. Local Climate Change Visioning and Landscape Visualizations: Guidance Manual. Collaborative for Advanced Landscape Planning, University of British 
Columbia, Vancouver, Canada. Available at: http://www.calp.forestry.ubc.ca/wpcontent/uploads/2010/02/CALP-Visioning-Guidance-Manual-Version-1.1.pdf

Program for Climate Model Diagnosis and Intercomparison (PCMDI). 2010. Webpage: CMIP5 - Modeling Info - Producing Model Output. Available at: http://cmippcmdi.llnl.gov/cmip5/output_req.html?submenuheader=2\#req_list

Ruosteenoja, Kimmo, T. R. Carter, K. Jylhä and H. Tuomenvirta. 2003. Future climate in world regions: an intercomparison of model-based projections for the new IPCC emissions scenarios. Finnish Environment Institute, Finnish Meteorological Institute, Helsinki, ISBN 952-11-1463-0 (nid.) 952-11-1464-9 (pdf).

Salter, J.D., C. Campbell, M. Journeay, S. R. J. Sheppard. 2009. The digital workshop: exploring the use of interactive and immersive visualisation tools in participatory planning. Journal of Environmental Management 90(6), 2090-2101.

Salter, J., Robinson J., Wiek A., 2010. Participatory methods of integrated assessment-a review. Wiley Interdisciplinary Review Climate Change 1, 697-717.

Schneider, S.H. 2001. What is "dangerous" climate change? Nature 411, 17-19.

Sharp, Darrin. 2010 (in draft). An Inventory of Approaches to Climate Modeling and Downscaling, Prepared for Piloting Utility Modeling Applications (PUMA) Workshop, San Francisco, CA, 1-3 December 2010.

Shaw A., S. Sheppard, S. Burch, D. Flanders, A. Wiek, et al. 2009. Making local futures tangible: Synthesizing, downscaling, and visualizing climate change scenarios for participatory capacity building. Global Environmental Change 19, 447-463.

Sheppard, S. R. J. 2005. Landscape visualization and climate change: The potential for influencing perceptions and behaviour. Environmental Science and Policy 8, 637-654.

Sheppard, S. R. J. 2006. Bridging the sustainability gap with landscape visualisation in community visioning hubs. Integrated Assessment 6(4), 79-108.

Sheppard, S.R.J., Shaw, A., Burch, S., Flanders, D. Wiek, A., Carmichael, J., Robinson, J., and Cohen, S. 2011. Future Visioning of Local Climate Change: A Framework for Community Engagement and Planning with Scenarios and Visualization. Futures 43(4), 400-412.

Tang, Zhenghong , Brody, Samuel D. , Quinn, Courtney , Chang, Liang and Wei, Ting. 2010. Moving from agenda to action: evaluating local climate change action plans. Journal of Environmental Planning and Management, 53: 1, $41-62$, doi 10.1080/09640560903399772.

Task Group on Data and Scenarios for Impact and Climate Assessment (TGICA). 2007. Proposed Request to the Standard Variables List for the Next Coordinated Climate Model Experiments. Available at http://www.mad.zmaw.de/IPCC_DDC/html/DOC14_AR5vars.pdf).

van Notten, P. W. F, J. Rotmans, M. B. A. van Asselt, and D. A. Rothman. 2003. An updated scenario typology. Futures 35, 423-443.

van Vuuren, Detlef, Keywan Riahi, Richard Moss, Jae Edmonds, Allison Thomson, Nebosja Nakicenovic, Tom Kram, Frans Berkhout, Rob Swart, Anthony Janetos, Steve Rose and Nigel Arnell. 2010. Developing new scenarios as a common thread for future climate research. Supporting material for the IPCC Workshop on Socioeconomic Scenarios, Berlin, November 2010. Available for download at http://www.ipccwg3.de/meetings/expert-meetings-and-workshops/WoSES

van Vuuren, D.P. et al.. 2008. Work Plan for Data Exchange Between the Integrated Assessment and Climate Modeling Community in Support of Phase-0 of Scenario 
Analysis for Climate Change Assessment (Representative Community Pathways). Available at http://www.aimes.ucar.edu/docs/RCP handshake.pdf.

Vervoort, J. M., K. Kok, R. Van Lammeren, T. Veldkamp. 2010. Stepping into futures: Exploring the potential of interactive media for participatory scenarios on socialecological systems. Futures 42(6), 604-616.

Weyant, J., O Davidson, H. Dowlatabadi, J. Edmonds, M. Grubb, E. A. Parson, R. Richels, J. Rotmans, P. R. Shukla, R. S. J. Tol, W. Cline, S. Frankhauser. 1996. Integrated assessment of climate change: An overview and comparison of approaches and results. In Climate Change 1995: Economic and Social Dimensions of Climate Change: Contribution of Working Group III to the Second Assessment Report of the Intergovernmental Panel on Climate Change, J. P. Bruce, H. Lee, and E. F. Haites (eds). Cambridge University Press, Cambridge, UK.

Wiek, A., C. Binder, R. W. Scholz. 2006. Functions of scenarios in transition processes. Futures 38, 740-766.

Wiek, A., et al., in prep. Participatory approaches for constructing and using the new generation of climate change scenarios - A methodological review.

Winn, W. 1997. The impact of three-dimensional immersive virtual environments on modern pedagogy. Human Interface Technology Laboratory Technical Report R-97-15, University of Washington, Seattle, WA

Zurek, M. and T. Henrichs. 2007. Linking scenarios across geographical scales in international environmental assessments. Technological Forecasting \& Social Change 74(8), 1282-1295, doi 10.1016/j.techfore.2006.11.005. 
